PREPARED FOR THE U.S. DEPARTMENT OF ENERGY, UNDER CONTRACT DE-AC02-76CH03073

PPPL-3578

PPPL-3578

UC-70

\author{
Localized Ballooning Modes \\ in Compact Quasiaxially Symmetric Stellarators \\ M.H. Redi, J. Canik, R.L. Dewar, E.D. Fredrickson, \\ W.A. Cooper, J.L. Johnson, S. Klasky
}

June 2001

NM|

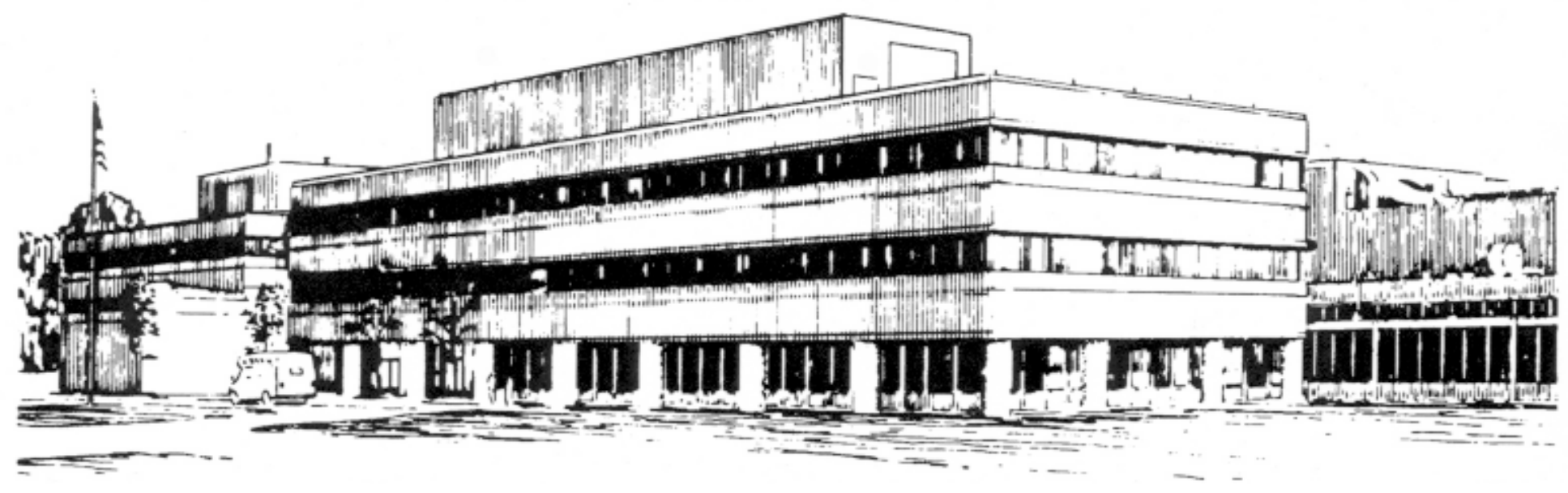

PRINCETON PLASMA PHYSICS LABORATORY PRINCETON UNIVERSITY, PRINCETON, NEW JERSEY 


\section{PPPL Reports Disclaimer}

This report was prepared as an account of work sponsored by an agency of the United States Government. Neither the United States Government nor any agency thereof, nor any of their employees, makes any warranty, express or implied, or assumes any legal liability or responsibility for the accuracy, completeness, or usefulness of any information, apparatus, product, or process disclosed, or represents that its use would not infringe privately owned rights. Reference herein to any specific commercial product, process, or service by trade name, trademark, manufacturer, or otherwise, does not necessarily constitute or imply its endorsement, recommendation, or favoring by the United States Government or any agency thereof. The views and opinions of authors expressed herein do not necessarily state or reflect those of the United States Government or any agency thereof.

\section{Availability}

This report is posted on the U.S. Department of Energy's Princeton Plasma Physics Laboratory Publications and Reports web site in Calendar Year 2001. The home page for PPPL Reports and Publications is: http://www.pppl.gov/pub_report/

DOE and DOE Contractors can obtain copies of this report from:

U.S. Department of Energy

Office of Scientific and Technical Information

DOE Technical Information Services (DTIS)

P.O. Box 62

Oak Ridge, TN 37831

Telephone: (865) 576-8401

Fax: (865) 576-5728

Email: reports@adonis.osti.gov

This report is available to the general public from:

National Technical Information Service

U.S. Department of Commerce

5285 Port Royal Road

Springfield, VA 22161

Telephone: 1-800-553-6847 or

(703) 605-6000

Fax: (703) 321-8547

Internet: http://www.ntis.gov/ordering.htm 


\title{
LOCALIZED BALLOONING MODES IN COMPACT QUASIAXIALLY SYMMETRIC STELLARATORS*
}

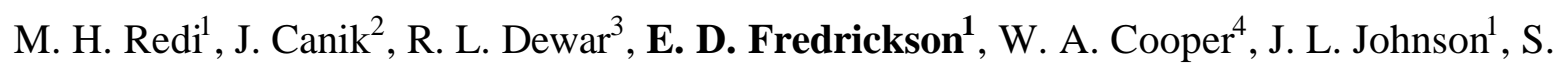

\author{
Klasky \\ ${ }^{1}$ Princeton Plasma Physics Laboratory, Princeton, NJ 08543 \\ ${ }^{2}$ Dept. of Electrical and Computer Engineering, University of Wisconsin, Madison, WI \\ ${ }^{3}$ Dept. of Theoretical Physics, The Australian National University, Canberra, Australia \\ ${ }^{4}$ Centre de Recherche en Physique des Plasmas, EPFL, Lausanne, Switzerland
}

\section{Introduction}

Understanding of ballooning mode stability boundaries may lead to performance improvement of toroidal devices through control of disruptions. Toroidally localized ballooning modes have been found as precursors to high beta disruptions on $\operatorname{TFTR}^{1}$ arising in conditions of $n=1$ kink mode asymmetry. Recent optimization has shown that magnetohydrodynamic stability as well as good particle confinement are likely to be achievable in the National Compact Stellarator Experiment (NCSX), a compact, quasiaxially symmetric stellarator (QAS) for values of the plasma near $\beta=4 \%^{2}$. The configuration, with a major radius of $1.42 \mathrm{~m}$, an aspect ratio of 4.4 , a toroidal magnetic field 1.2-1.7 $\mathrm{T}$ and 6MW of neutral beam heating, is stable to MHD instabilities, and is expected to be limited by high- $n$ kink and ballooning modes. This paper describes the ballooning eigenvalue isosurfaces for NCSX, the first step in an examination of the kinetic stabilization of the ballooning beta limit using a hybrid WKB approach ${ }^{3}$.

\section{Eigenvalue Isosurfaces of the Quasiaxially Symmetric Stellarator}

The VVBAL module of the TERPSICHORE code suite ${ }^{4}$ has been used to calculate the ballooning instability for several NCSX equilibria (Fig. 1) above the design point ( $\beta=$ 4.1\%) with the VMEC code. The displacement of the flux surface grows with growth rate $\gamma ; \xi \propto \exp (i \omega t) \propto \exp (\gamma \mathrm{t})$. We define the eigenvalue $\lambda=-\omega^{2}$; positive values of $\lambda$ denote instability, while negative values denote stability. For $\beta=4.3 \%$ and $\beta=6.8 \%$ we have assembled a datacube of ballooning eigenvalues $\lambda\left(s, \alpha, \theta_{k}\right)$, of size $(126,101,21)$. $\quad s$ is the toroidal flux, $\alpha$ is the field line variable. Roughly, within $\pm \pi$, the ballooning parameter $\theta_{\mathrm{k}}$ determines where the eigenfunction is a maximum. Figure 2 shows the plasma iota of the two equilibria. These are weak shear plasmas, with vanishing shear near the edge. 
The isosurfaces of $\lambda$ describe the possible trajectories of rays of the ballooning equation. Consequently they characterize the quantization conditions that are used to find the maximum wave vector, and thereby kinetic stabilization of the ballooning beta limit. The QAS isosurfaces are found to exhibit unusual and unique topologies for the two configurations. Distinct structures occur in different ranges of $\lambda$ in the stable spectrum: a) at $\lambda=-0.15$, a helical structure is found near the plasma edge, rotating about an axis nearly parallel to? the $\theta_{\mathrm{k}}$ axis, with fins stretching toward the plasma center; b) at $\lambda=-0.45$, cylinders are found nearly constant in $\theta_{\mathrm{k}}$, localized in s and $\alpha$. At $\beta=6.8 \%$, similar structures in the stable spectrum occur, although more global in extent.

The unstable spectra are less complex, consisting primarily of planes and topologically cylindrical and spherical isosurfaces near the outer edge of the plasma, where shear goes to zero and the instability is more easily driven. In general, there is a weak dependence on the ballooning angle $\theta_{\mathrm{k}}$, stronger dependence on the field line $\alpha$ and quite strong dependence on the radial parameter s. At $\beta=4.3 \%$ topologically spherical isosurfaces are found for the maximum eigenvalues, indicative of strong quantum $\operatorname{chaos}^{3}$. This description "quantum chaos" for the paths of rays of the ballooning equation does not mean that the plasma behavior is chaotic, but that the mathematics of a quantum chaotic scattering problem can be used for instabilities far above the marginal point of the equilibrium. At lower values of the eigenvalue, isolated unstable cylindrical and planar isosurfaces conjoin, as the eigenvalue $\lambda$ drops to zero, and the isosurface is no longer simply connected. At $\beta=6.8 \%$ the bands break up at maximum eigenvalues. The configuration is Mercier stable at both values of $\beta$.

Comparison with a related axisymmetric tokamak shows that the structures of the stable and unstable spectra of the QAS arise from the complexity of the magnetic configuration.

\section{Finite Larmor Radius Stabilization of the Beta Limit}

In practice, only finite- $n$ modes can be unstable due to finite ion Larmor radius (FLR) stabilization. Finite- $n$ ballooning mode stability calculations with a three-dimensional, linear MHD code for a two-field period QAS configuration showed that the finite $n$ ballooning modes $(n \sim 20)$ are significantly more stable than the infinite- $n$ results. For H1 and LHD finite $n$ ballooning modes have been examined by applying the WKB ballooning formalism and semi-classical quantization or quantum chaos theory, depending on the 
topology of the isosurfaces ${ }^{3}$. The validity of the hydrodynamic, fluid model for MHD breaks down and kinetic corrections are required if the condition $\left(\mathrm{k}_{\perp} \rho_{\mathrm{i}}\right)^{2}<<1$ is not satisfied. Here $k_{\perp}$ is the wave vector perpendicular to the field line, and $\rho_{i}$ is the ion Larmor radius, which for the QAS is $\sim 1 \mathrm{~cm}$. Near the beta limit the ballooning rays at the marginal point $(\lambda=0)$ will propagate on an isosurface having topology of conjoined cylinders, with axes parallel to $\theta_{\mathrm{k}}$. It does not appear that either the Einstein-Keller-Brillouin semiclassical quantization method or the quantum chaos approach applies.

\section{Anderson localization}

Symmetry breaking localization of the ballooning mode in stellarator plasmas has been identified for LHD, $\mathrm{H} 1$ and $\mathrm{HSX}^{5}$ as analogous to Anderson localization ${ }^{6}$ of electron eigenfunctions in condensed matter. Our calculations show that localization of the QAS eigenfunction increases for reduced plasma shear (Fig. 3). Each flux surface has a different shape, changing the poloidal angle at which the eigenfunction is maximized. Weak shear increases localization of the eigenfunction, in contrast to the tokamak case ${ }^{7}$. The most localized modes in this geometry occur in the region where global magnetic shear is weakest, including at the shear reversal surface itself, demonstrating the existence of Anderson localization in the QAS.

\section{Conclusion}

We find Anderson localization of the ballooning mode in the QAS and have obtained eigenvalue isosurfaces with which to examine kinetic stabilization of $\beta$. A new method of regularizing the eigenfunction to estimate $\mathrm{k}_{\perp}$ will be needed for the QAS at the beta limit, since the topology of the marginal point isosurfaces is not simply connected.

1. E. Fredrickson, et al., Phys. Plas. 3, 2620 (1996).

2. A. H. Reiman, et al. Phys. Plas. 8, 2083 (2001).

3. R. L. Dewar, P. Cuthbert, R. Ball, Phys. Rev. Lett. 86, 2321 (2001).

4. D. V. Anderson, et al. in "Theory of Fusion Plasmas", I. F-E C. Bologna, (1988) p93.

5. C. Hegna, S. Hudson, to appear in Phys. Rev. Lett. (2001).

6. P. W. Anderson, Phys. Rev. 109, 1492 (1958).

7. P. Cuthbert, R. L. Dewar, Phys. Plas. 7, 2302 (2001).

* Research supported by U. S. DOE Contract DE-AC02-76CH03073. John Canik held a DOE National Undergraduate Fellowship at PPPL during summer, 2000 


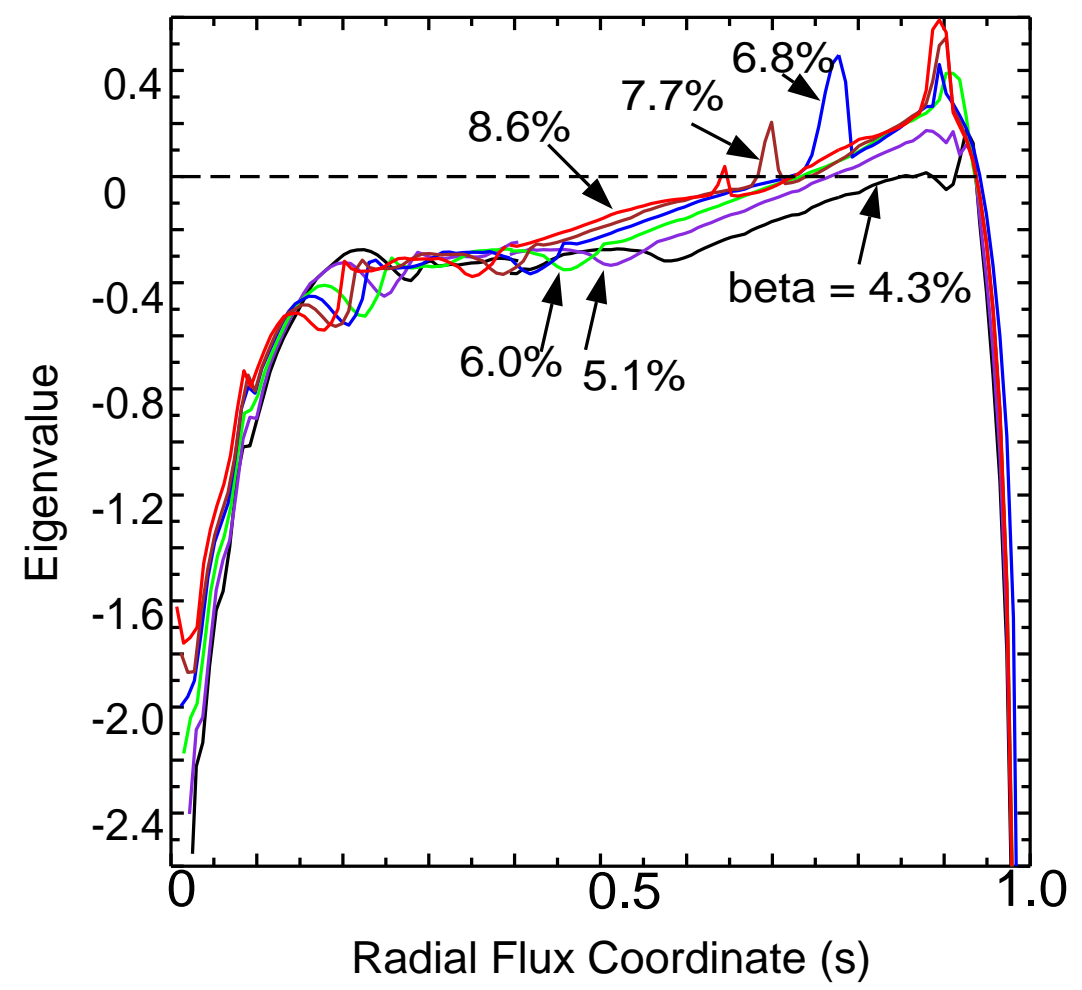

Figure 1. Ballooning eigenvalues for NCSX above the design point. $\alpha=0, \theta k=0$.
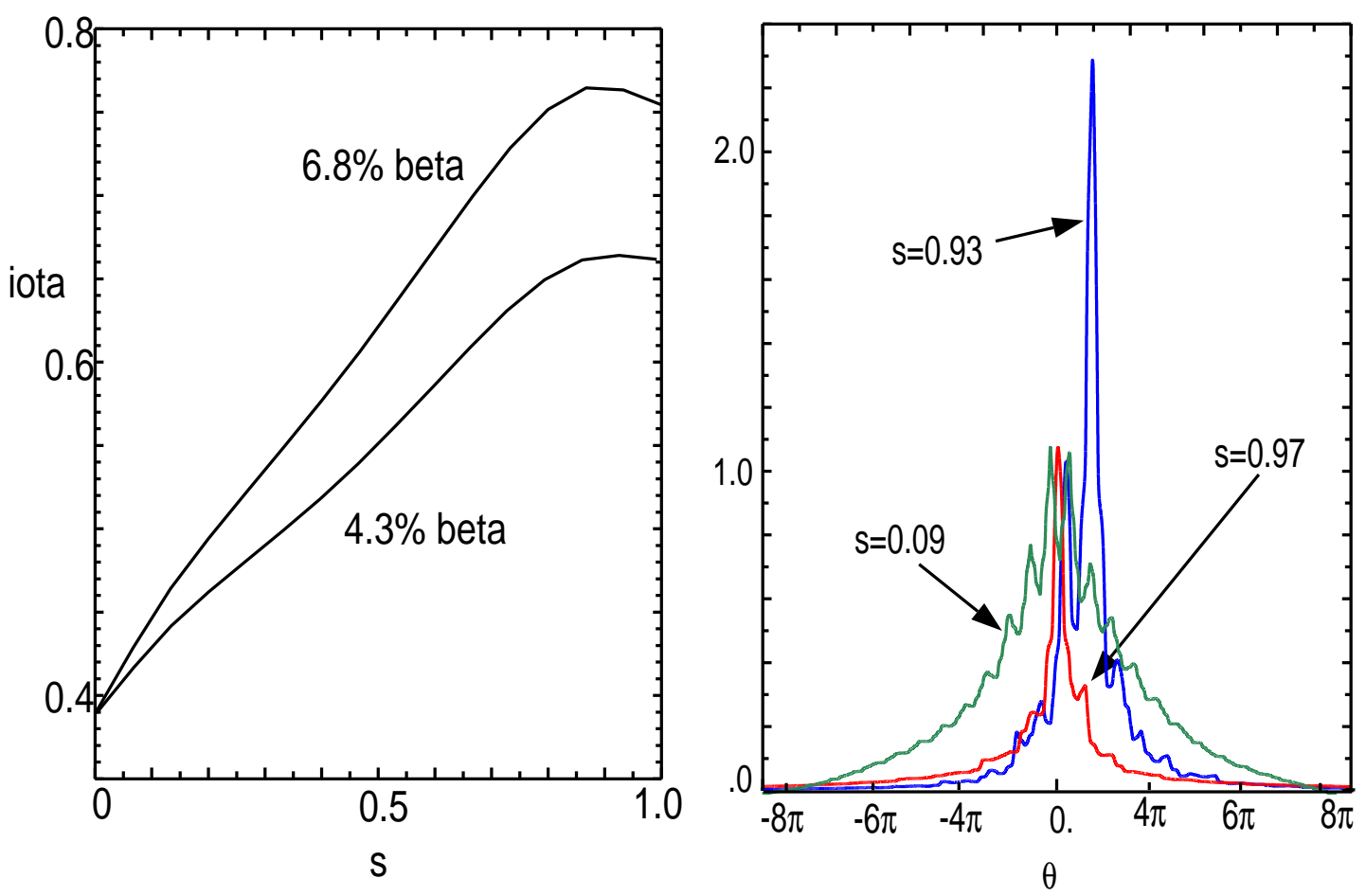

Figure 2. Iota profiles for equilibria above the design point beta.

Figure 3. Eigenfunction localization in poloidal angle near the plasma edge, labeled by s, the edge normalized toroidal flux. 


\section{External Distribution}

Plasma Research Laboratory, Australian National University, Australia

Professor I.R. J ones, Flinders University, Australia

Professor J oão Canalle, Instituto de Fisica DEQ/IF - UERJ , Brazil

Mr. Gerson O. Ludwig, Instituto Nacional de Pesquisas, Brazil

Dr. P.H. Sakanaka, Instituto Fisica, Brazil

The Librarian, Culham Laboratory, England

Library, R61, Rutherford Appleton Laboratory, England

Mrs. S.A. Hutchinson, JET Library, England

Professor M.N. Bussac, Ecole Polytechnique, France

Librarian, Max-Planck-Institut für Plasmaphysik, Germany

J olan Moldvai, Reports Library, MTA KFKI-ATKI, Hungary

Dr. P. Kaw, Institute for Plasma Research, India

Ms. P.J . Pathak, Librarian, Insitute for Plasma Research, India

Ms. Clelia De Palo, Associazione EURATOM-ENEA, I taly

Dr. G. Grosso, Instituto di Fisica del Plasma, Italy

Librarian, Naka Fusion Research Establishment, J AERI, J apan

Library, Plasma Physics Laboratory, Kyoto University, J apan

Research Information Center, National Institute for Fusion Science, J apan

Dr. O. Mitarai, Kyushu Tokai University, J apan

Library, Academia Sinica, Institute of Plasma Physics, People's Republic of China

Shih-Tung Tsai, Institute of Physics, Chinese Academy of Sciences, People's Republic of China

Dr. S. Mirnov, TRINITI, Troitsk, Russian Federation, Russia

Dr. V.S. Strelkov, Kurchatov Institute, Russian Federation, Russia

Professor Peter Lukac, Katedra Fyziky Plazmy MFF UK, Mlynska dolina F-2, Komenskeho Univerzita, SK-842 15 Bratislava, Slovakia

Dr. G.S. Lee, Korea Basic Science Institute, South Korea

Mr. Dennis Bruggink, Fusion Library, University of Wisconsin, USA

Institute for Plasma Research, University of Maryland, USA

Librarian, Fusion Energy Division, Oak Ridge National Laboratory, USA

Librarian, Institute of Fusion Studies, University of Texas, USA

Librarian, Magnetic Fusion Program, Lawrence Livermore National Laboratory, USA

Library, General Atomics, USA

Plasma Physics Group, Fusion Energy Research Program, University of California at San Diego, USA

Plasma Physics Library, Columbia University, USA

Alkesh Punjabi, Center for Fusion Research and Training, Hampton University, USA

Dr. W.M. Stacey, Fusion Research Center, Georgia Institute of Technology, USA

Dr. J ohn Willis, U.S. Department of Energy, Office of Fusion Energy Sciences, USA

Mr. Paul H. Wright, Indianapolis, Indiana, USA 
The Princeton Plasma Physics Laboratory is operated by Princeton University under contract with the U.S. Department of Energy.

\author{
Information Services \\ Princeton Plasma Physics Laboratory \\ P.O. Box 451 \\ Princeton, NJ 08543
}

Phone: 609-243-2750

Fax: 609-243-2751

e-mail: pppl_info@pppl.gov

Internet Address: http://www.pppl.gov 